\section{Исследование взаимодействия транспортных средств и элементов путей первичного транспорта леса}

\author{
А. В. Кузнецов ${ }^{1}$ \\ Петрозаводский государственный университет
}

\section{АННОТАЦИЯ}

В статье приведены результаты исследования взаимодействия транспортных машин и элементов путей первичного транспорта леса (волока, лесовозного уса). Проведен анализ функционирования систем машин в условиях лесозаготовительного предприятия, который показывает возможность снижения затрат на их строительство и эксплуатацию с учетом местных климатических, технических, технологических, сырьевых условий.

Ключевые слова: лесной транспорт, временные дороги, строительство.

\section{SUMMARY}

The research of interaction of transport machines and elements of ways of primary wood transportation (temporary forest roads, haul road feeders) including the analysis of machine systems functioning at a logging enterprise allows to decrease expenses for their construction and operation taking into account local climatic, technical, technological conditions and availability of raw materials.

Keywords: forest transport, temporary road, construction.

В теории разрушения почв наиболее важный вопрос установление зависимости напряжений от деформаций. При механико-математическом исследовании рассматривают почву как среду [2]:

1) упругую и пластичную;

2) характеризующуюся нелинейной зависимостью напряжений от деформации.

Нелинейный характер деформации грунта под нагрузкой выражается законом Винклера-ГерстенаБернштейна [1]:

$$
q=A \cdot Z^{n}
$$

где $q$ - напряжение $H / \mathrm{M}^{2}$; $A$ - коэффициент объемного сжатия; $n$ - показатель процесса нагрузка-осадка; $Z$ - осадка, $м$.

Параметры $A$ и $n$ полагаются постоянными для данного грунта. В действительности они изменяются в

\footnotetext{
${ }_{1}^{1}$ Автор - аспирант кафедры технологии и оборудования лесного комплекса
}

(C) А. В. Кузнецов, 2003 зависимости от размеров штампа, что вызывает трудности, связанные с практическим применением формулы (1). Параметры $A$ и $n$ - эмпирические константы.

Формула (1) не может быть использована для выражения зависимости деформации грунта при больших диапазонах изменения нагрузки и размеров штампа и применима лишь в конкретных условиях. Кроме этого, она не учитывает влияния размеров штампа на деформируемость грунта.

Сделано много попыток заменить формулу (1) приемлемой для практического использования. В частности, Беккер [2] записал (1) виде:

$$
q=\left(\frac{K_{c}}{b}-K_{\varphi}\right) \cdot Z^{n},
$$

где $\boldsymbol{K}_{\boldsymbol{C}}$ и $\boldsymbol{K}_{\boldsymbol{\varphi}}{ }^{-}$соответственно коэффициенты сцепления и трения грунтов; $b$ - наименьший размер штампа, $\mathcal{M}$.

Рассмотрим формулы для деформируемости грунта, предложенные для различных типов движителей, учитывающие размеры штампа.

Среднее нормальное давление на опорную поверхность гусеничного движителя, согласно Г. М. Анисимову, Я. С. Агейкину, В. Ф. Платонову и др., определяется по формуле [1]:

$$
q^{\prime}=\frac{G_{\Gamma}}{B_{\Gamma} \cdot L_{\Gamma}},
$$

где $G_{\Gamma}$ - нормальная нагрузка на гусеницы, $H ; B_{\Gamma}-$ ширина гусеницы, $\mathcal{M} ; L_{\Gamma}$ - длина опорной поверхности гусеницы, $\boldsymbol{M}$.

Среднее нормальное давление на опорную поверхность колесного движителя, согласно Г. М. Анисимову, С. С. Саакяну, определяется по формуле [1]:

$$
q^{\prime}=C_{u} \cdot P_{u}^{r}
$$

где $C_{u}-$ коэффициент, характеризующий жесткость шины, H; $r$ - показатель, $M$; $P_{u}$ - давление воздуха в шинах, $H / M^{2}$.

Приведенные зависимости учитывают распространение напряжений в чистом грунте, без примесей, но применение на путях первичного транспорта леса хворостяной подушки существенно меняет параметры давления движителя на почвогрунты (рис. 1).

При укреплении путей первичного транспорта леса лесосечными отходами увеличивается площадь контакта движителя и почвогрунта за счет увеличения площади штампа. Следовательно, необходим коэффициент, учитывающий наличие хворостяной подушки: 


$$
K_{л о}=\frac{S_{u}}{S_{\kappa}},
$$

где $S_{k}, S_{u}$ - площадь конгломерата и штампа соответственно, $M^{2}$.
Считаем, что слой лесосечных отходов ведет себя как монолит и составляющие хворостяной подушки испытывают лишь вертикальные деформации и смещения.

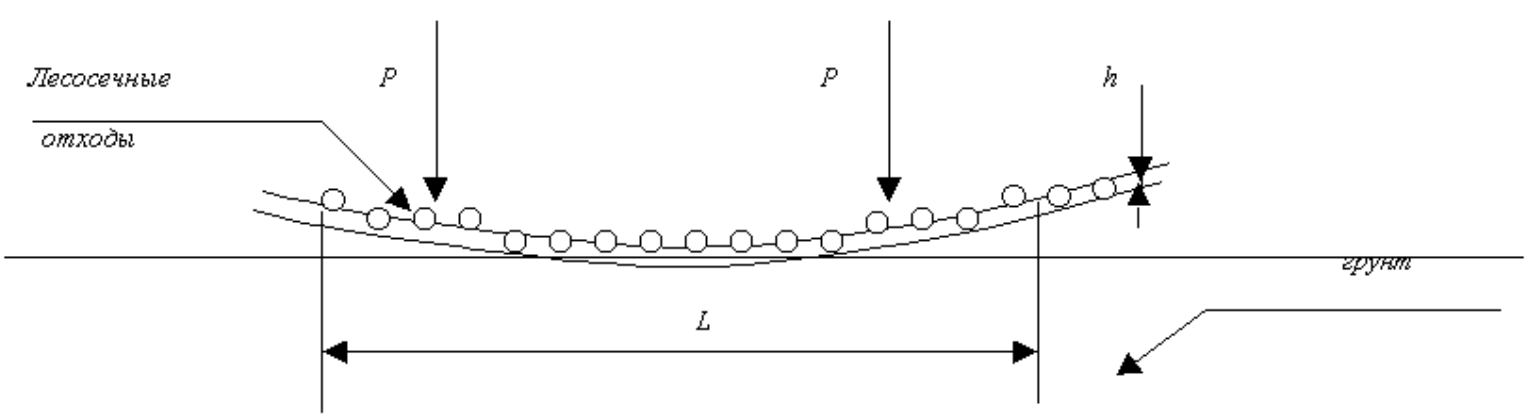

Рис. 1. Схема воздействия движителя на почвогрунты

Расчет несущей способности хворостяной подушки и почвогрунтов на начальном этапе (до 10 проходов) можно вести по зависимостям, характеризующим несущую способность ленточных фундаментов мелкого заложения с шероховатой поверхностью без учета пригрузки.

Согласно проведенным исследованиям после 10 проходов лесной машины по транспортному пути, укрепленному лесосечными отходами, образуется конгломерат - смесь почвогрунта с лесосечными отходами. В этом случае необходимо рассматривать поверхность, по которой совершает движение лесная машина, как почвогрунт, армированный лесосечными отходами, расположенными горизонтально.

В зависимости от типов местности по условию увлажнения предлагаются следующие зависимости:

Для гусеничных машин:

- первый тип местности, относительная влажность менее 0,75 :

$q=\frac{\left(\frac{K_{c}}{B_{\Gamma} \cdot L_{\Gamma}}+K_{\varphi}\right) \cdot\left(\frac{\frac{G_{\Gamma}}{2 \cdot B_{\Gamma} \cdot L_{\Gamma}} \cdot k_{n 0} \cdot K \cdot(1+B \cdot N+C \cdot \ln N}{-}\right)^{n}}{1+\frac{S_{\kappa}}{2 \cdot B_{\Gamma} \cdot L_{\Gamma}}}$,

где $K$ - эмпирический коэффициент; $A, B$ и $C$ - коэффициенты, зависящие от параметров ходовой части машин и свойств почвогрунтов; $E$ - модуль деформации грунта, $M \Pi a ; N$ - число проходов;

- второй тип местности, относительная влажность от 0,75 до 0,90 :

$$
q=\frac{\left(\frac{K_{c}}{B_{\Gamma} \cdot L_{\Gamma}}+K_{\varphi}\right) \cdot\left(\frac{\frac{G_{\Gamma}}{2 \cdot B_{\Gamma} \cdot L_{\Gamma}} \cdot k_{л 0} \cdot K \cdot(A+B \cdot \ln N}{-}\right)^{n}}{1+\frac{S_{K}}{2 \cdot B_{\Gamma} \cdot L_{\Gamma}}} ;(7)
$$

- $\quad$ третий тип местности, относительная влажность более 1,00 :

$$
q=\frac{\left(\frac{K_{c}}{B_{\Gamma} \cdot L_{\Gamma}}+K_{\varphi}\right) \cdot\left(\frac{\frac{G_{\Gamma}}{2 \cdot B_{\Gamma} \cdot L_{\Gamma}} \cdot k_{n o} \cdot K \cdot(A+B \cdot N}{-}\right)^{n}}{1+\frac{S_{\kappa}}{2 \cdot B_{\Gamma} \cdot L_{\Gamma}}} .
$$

Для колесных машин:

- первый тип местности, относительная влажность менее 0,75 :

$$
q=\frac{\left(\frac{K_{c}}{F_{u}}+K_{\varphi}\right) \cdot\left(\frac{C_{u} \cdot 6 \cdot P^{r} \cdot k_{л 0} \cdot K \cdot(A+B \cdot N+C \cdot \ln N}{E}\right)^{n}}{1+\frac{S_{K}}{6 \cdot F_{u}}} ;
$$

- $\quad$ второй тип местности, относительная влажность от 0,75 до 0,90 : 


$$
q=\frac{\left(\frac{K_{c}}{F_{u}}+K_{\varphi}\right) \cdot\left(\frac{C_{u} \cdot 6 \cdot P^{r} \cdot k_{\pi 0} \cdot K \cdot\left(1+B \cdot \ln N^{\prime}\right.}{E}\right)^{n}}{1+\frac{S_{K}}{6 \cdot F_{u}}}
$$

- третий тип местности, относительная влажность более 1,00 :

$$
q=\frac{\left(\frac{K_{c}}{F_{u}}+K_{\varphi}\right) \cdot\left(\frac{C_{u} \cdot 6 \cdot P^{r} \cdot K_{n o} \cdot K \cdot\left(1+B \cdot N^{-}\right.}{E}\right)^{n}}{1+\frac{S_{\kappa}}{6 \cdot F_{u}}} .
$$

\section{Гусеничиве манины $(W<0,75)$}

\section{$\mathrm{g}, \boldsymbol{I I a}$}

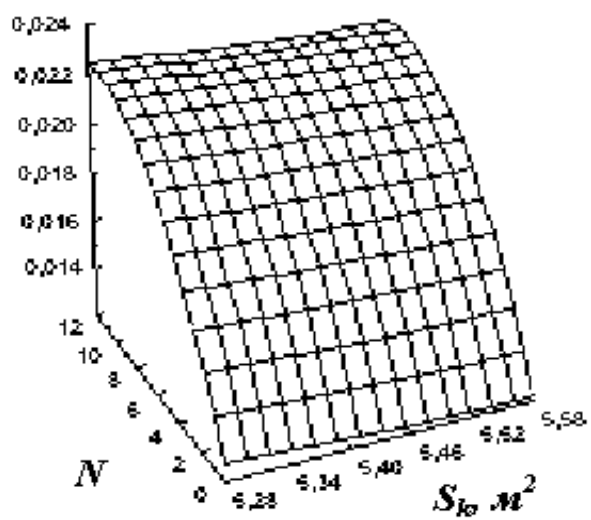

На основе уравнений разработаны таблицы объемов лесосечных отходов в зависимости от типа местности (табл. 1, 2).

Зависимость напряжений в почвогрунте от числа проходов (относительная влажность менее 0,75 , песок), представлена на рис. 2

Рис. 2. Характер распределения напряжений в зависимости от числа проходов (первый тип местности)

\begin{tabular}{|c|c|c|c|c|c|c|}
\hline \multirow{2}{*}{$\begin{array}{c}\text { Расположение лесосечных от- } \\
\text { ходов (ЛО) }\end{array}$} & \multirow{2}{*}{ К } & \multicolumn{5}{|c|}{ Масса ЛО, кг/м² } \\
\hline & & песок & супесь & суглинок & глина & торф \\
\hline 1 & 2 & 3 & 4 & 5 & 6 & 7 \\
\hline \multicolumn{7}{|c|}{ I тип, влажность менее 0,75} \\
\hline Параллельно & 1 & 25 & 26 & 38 & 295 & 553 \\
\hline Перпендикулярно & 0,725 & 25 & 26 & 38 & 295 & 553 \\
\hline Внахлест & 0,723 & 25 & 26 & 38 & 295 & 553 \\
\hline \multicolumn{7}{|c|}{ II тип, влажность от 0,75 до 0,9} \\
\hline Параллельно & 1 & 100 & 104 & 154 & 1186 & 2221 \\
\hline Перпендикулярно & 0,725 & 100 & 104 & 154 & 1186 & 2221 \\
\hline
\end{tabular}

Необходимое количество лесосечных отходов (гусеничные машины) 


\begin{tabular}{|c|c|c|c|c|c|c|c|}
\hline & 2 & 3 & 4 & 5 & 6 & 7 \\
\hline Внахлест & 0,723 & 100 & 104 & 154 & 1186 & 2221 \\
\hline \multicolumn{7}{|c|}{ III тип, влажность более 1,0} \\
\hline Параллельно & 1 & 112 & 116 & 171 & 1320 & 2471 \\
\hline Перпендикулярно & 0,725 & 112 & 116 & 171 & 1320 & 2471 \\
\hline Внахлест & 0,723 & 112 & 116 & 171 & 1320 & 2471 \\
\hline
\end{tabular}

Таблица 2

Необходимое количество лесосечных отходов (колесные машины)

\begin{tabular}{|c|c|c|c|c|c|c|}
\hline \multirow{2}{*}{$\begin{array}{c}\text { Тип местности и расположение } \\
\text { лесосечных отходов (ЛО) }\end{array}$} & \multirow[t]{2}{*}{ K } & \multicolumn{5}{|c|}{ Масса ЛО, кг/м² } \\
\hline & & песок & супесь & суглинок & глина & торф \\
\hline \multicolumn{7}{|c|}{ I тип, влажность менее 0,75} \\
\hline Параллельно & 1 & 60 & 62 & 92 & 709 & 1327 \\
\hline Перпендикулярно & 0,725 & 60 & 62 & 92 & 709 & 1327 \\
\hline Внахлест & 0,721 & 60 & 62 & 91 & 707 & 1323 \\
\hline \multicolumn{7}{|c|}{ II тип, влажность от 0,75 до 0,9} \\
\hline Параллельно & 1 & 225 & 234 & 344 & 2655 & 4970 \\
\hline Перпендикулярно & 0,725 & 225 & 234 & 344 & 2656 & 4973 \\
\hline Внахлест & 0,721 & 224 & 233 & 343 & 2648 & 4958 \\
\hline \multicolumn{7}{|c|}{ III тип, влажность более 1,0} \\
\hline Параллельно & 1 & 249 & 259 & 381 & 2946 & 5515 \\
\hline Перпендикулярно & 0,725 & 249 & 259 & 381 & 2947 & 5518 \\
\hline Внахлест & 0,721 & 249 & 259 & 380 & 2938 & 5502 \\
\hline
\end{tabular}

\section{ВЫВОДЫ}

1. При укладке лесосечных отходов параллельно, перпендикулярно и внахлест происходит уменьшение значений линейных перемещений в 2,8; 3,9 и 3,9 раза соответственно. Перемещения при укладке лесосечных отходов перпендикулярно и внахлест практически не отличаются. Следовательно, при укладке лесосечных отходов необходимо придерживаться перпендикулярной схемы расположения хворостяной подушки.

2. Толщина хворостяной подушки 10-20 см обеспечивает (полевые испытания) уменьшение интенсивности колееобразования: в 2,79 раза при укладке лесосечных отходов параллельно, в 3,85 раза при укладке перпендикулярно, в 3,86 раза при укладке внахлест. В лабораторных условиях разница составила 1,19 раза. Необходимый объем лесосечных отходов - от 75 до $900 \mathrm{~m}^{3}$ на 1 км в зависимости от вида почво-грунтов.

\section{СПИСОК ЛИТЕРАТУРЫ}

1. Анисимов Г. М., Большаков Б. М. Основы минимизации уплотнения почвы трелевочными системами / СПбГЛТА. СПб., 1998. 108 с.

2. Беккер М. Г. Введение в теорию систем местность - машина. М.: Машиностроение, 1973. 520 с. 